D metabolites in phosphate transport of rat intestine. J. Nutr., 104: 1056 (1974).

8. Condon, J. R., Nassim, J. R., and Rutter, A.: Pathogenesis of rickets and osteomalacia in familial hypophosphatemia. Arch. Dis. Childhood, 46: 269 (1971).

9. Dent, D. E.: Rickets and osteomalacia from renal tubule defects. J. Bone Joint Surg., 34B: 226 (1952).

10. Foulkes, E. C.: Effects of heavy metals on renal aspartate transport and the nature of solute movement in kidney cortex slices. Biochim. Biophys. Acta, 241: 814 (1971).

11. Fanconi, A., Fischer, J. A., and Prader, A.: Serum parathyroid hormone concentrations in hypophosphataemic vitamin D resistant rickets. Helv. Paediat. Acta, 29: 187 (1974).

12. Gerbeaux-Balsan, S.: L'absorption intestinale du phosphore dans le rachitisme vitamino-résistant hypophosphatémique héréditaire: Effets de fortes surcharges de phosphore et des régimes très pauvres en calcium. Rev. Franç. Clin. Biol., 10: 65 (1965).

13. Glorieux, F. H., and Scriver, C. R.: Loss of a parathyroid hormone-sensitive component of phosphate transport in X-linked hypophosphatemia. Science, 175: 997 (1972),

14. Glorieux, F. H., Scriver, C. R., Delvin, E., and Mohyuddin, F.: Transport and metabolism of sarcosine in hypersarcosinemic and normal phenotypes. J. Clin, Invest., 50: 2313 (1971)

15. Glorieux, F. H., Scriver, C. R., Eicher, E. M., Southard, J. L., and Travers, R.: $\mathrm{X}$-linked hypophosphatemia in Hyp/y mouse, a model of the human disease [Abstract]. Pediat. Res., 8: 899 (1974).

16. Glorieux, F. H., Scriver, C. R., Holick, M. F., and DeLuca, H. F.: X-linked hypophosphataemic rickets: Inadequate therapeutic response to 1,25-dihydroxycholecalciferol. Lancet, ii: 287 (1973).

17. Glorieux, F. H., Scriver, C. R., Reade, T. M., Goldman, H., and Roseborough, A.: Use of phosphate and vitamin D to prevent dwarfism and rickets in X-linked hypophosphatemia. N. Engl. J. Med., 287: 481 (1972).

18. Greenberg, B. G., Winters, R. W., and Graham, J. B.: The normal range of serum inorganic phosphorus and its utility as a discriminant in the diagnosis of congenital hypophosphatemia. J. Clin. Endocrinol. Metab., 20: 364 (1960).

19. Gunther, L., Cohn, E. T., and Greenberg, D. V.: Metabolism of bone salts in resistant rickets. Amer. J. Dis. Child., 66: 517 (1943).

20. Haddad, J. G., and Chyu, K. J.: Competitive protein-binding radioassay for 25-hydroxycholecalciferol. J. Clin. Endocrinol., 33: 992 (1971).

21. Harrison, H. E., and Harrison, H. C.: Intestinal transport of phosphate: Action of vitamin D, calcium and potassium. Amer. J. Physicl., 201: 1007 (1961).

22. Harrison, H. E., and Harrison, H. C.: Sodium, potassium and intestinal transport of glucose, l-tyrosine, phosphate and calcium. Amer. J. Physiol., 205: 107 (1963).

23. Hurwitz, S., and Bar, A.: Site of vitamin D action in chick intestine. Amer. J. Physiol., 222: 761 (1972).

24. Kowarski, S., and Schachter, D.: Effects of vitamin D on phosphate transport and incorporation into mucosal constituents of rat intestinal mucosa. J. Biol. Chem., 244: 211 (1969).

25. Lewy, J. E., Cabana, E., Repetto, H. A., Canterbury, J. M., and Reiss, E.: Serum parathyroid hormone in hypophosphatemic vitamin D-resistant rickets. J. Pediat., 81: 294 (1972).

26. Rosenberg, L. E.: Hereditary diseases with membrane defects. In: R. M. Dowben: Biological Membranes, pp. 255-285 (Little Brown, Boston. 1969).

27. Short, E. M., Binder, H. J., and Rosenberg, L. E.: Familial hypophosphatemic rickets: Defective transport of inorganic phosphate by intestinal inucosa. Science, 179: 700 (1973).

28. Stickler, G. B.: External calcium and phosphorus balances in vitamin D resistant rickets. J. Pediat., 63: 942 (1963)

29. Tenenhouse, H. S., and Scriver, C. R.: Orthophosphate transport in the erythrocyte of normal subjects and of patients with X-linked hypophosphatemia. J. Clin. Invest., 55: 644 (1975)

30. Vestergaard-Bogind, B.: Determination on a micro scale of concentration and specific radioactivity of inorganic phosphate ions in whole blood and packed red cells. Scand. J. Clin. Lab. Invest., 157: 457 (1964).

31. Wasserman, R. H., and Taylor, A. N.: Intestinal absorption of phosphate in the chick: Effect of vitamin $\mathrm{D}_{3}$ and other parameters. J. Nutr., 103: 586 (1973).

32. Kindly given to us by Dr. Claude Arnaud.

33. We are grateful to Mireille Dussault for the technical assistance, and to Jeannine Mikan for assistance with the manuscript.

34. Dr. F. H. Glorieux is a Scientist of the Queen Elizabeth II Canadian Research Fund to aid in research on the diseases of children.

35. This research was supported by the Shriners of North America, Grant M3320 of the Medical Research Council of Canada, Grant 720143 of the Conseil de la recherche en Santé du Québec, and la Fondation Lacoste-Beaubien.

36. Requests for reprints should be addressed to: F. H. Glorieux, M.D., Ph.D., The Genetics Unit, Shriners Hospital for Crippled Children, 1529 Cedar Ave., Montreal H3G 1 A6 (Canada).

37. Accepted for publication January 14, 1976.

\title{
The Transplacental Migration and Accumulation in Blood of Volatile Organic Constituents
}

\author{
B. J. DOWTY AND J. L. LASETER ${ }^{129}$ \\ University of New Orleans, Department of Biological Sciences, New Orleans, Louisiana, USA \\ J. STORER
}

Charity Hospital of Louisiana at New Orleans, New Orleans, Louisiana, USA

Extract

Gas chromatographic-mass spectrometric analysis of profiles of low molecular weight volatile organic constituents obtained from cord blood and maternal blood samples collected at birth reflect transplacentally acquired compounds. The transplacental passage of halogenated hydrocarbons, plastic components, and abnormal accumulations of compounds have been demonstrated. In the 11 paired cord blood-maternal blood samples analyzed, the relative amounts of constituents in cord blood closely correspond to those quantities present in the maternal blood. However, some of the over 100 components are present in the cord blood in significantly higher concentrations than in the maternal blood, suggesting a possible selective one-way transfer of certain constituents into the fetus. Benzene, carbon tetrachloride, and chloroform are present in quantities equal to or greater than in maternal blood. In one infant with a lumbosacral meningomyelocele abnormally high concentrations of acetone, other components, and the food preservative 2,6-di-tert-butyl-4-methylphenol (BHT) were identified. 


\section{Speculation}

The relationship and significance of halogenated hydrocarbons, plastic components, and abnormal accumulations of compounds as they apply to appropriate intrauterine growth and development, propensity for developing cancer later in life, and well being are unknown. Similar techniques may be useful in monitoring the therapy of certain metabolic diseases as well as in elucidating the pathogenesis of clinical abnormalities noted in infants born to mothers with metabolic aberrations.

Recent analytic advances in gas chromatography and mass spectrometry have allowed the application of these techniques to the study of complex biologic mixtures. Research efforts using these techniques to study and elucidate certain disease states in the human have been limited and frequently publicized among audiences interested primarily in the analytic methods used.

The clinical value of metabolic profiling and early disease detection has been achieved mostly through the efforts of Horning and Horning (12), Jellum et al. (16), Robinson et al. (22), and Markey et al. (18). Problems involving a dysfunction in a particular metabolic step, thus leading to an accumulation in the excretion of certain products, lend themselves well to study by gas chromatographic-mass spectrometric (GC-MS) analyses. Using several extraction, fractionation, concentration, and derivatization procedures, extracts from urine have been used for analysis by GC-MS. Work of this type has been successful in establishing normal metabolic profiles and in detecting variations in these profiles associated with certain errors in metabolism. Hartnup's disease, maple syrup urine disease, isovaleric acidemia, and Refsum's disease are examples of the over 40 errors in metabolism which can be detected and diagnosed using these techniques (16).

Although valuable medical information has been obtained by previous researchers, it appears that the extraction, fractionation, concentration, and derivatization procedures used before their GC-MS analyses were rather cumbersome and did not lend

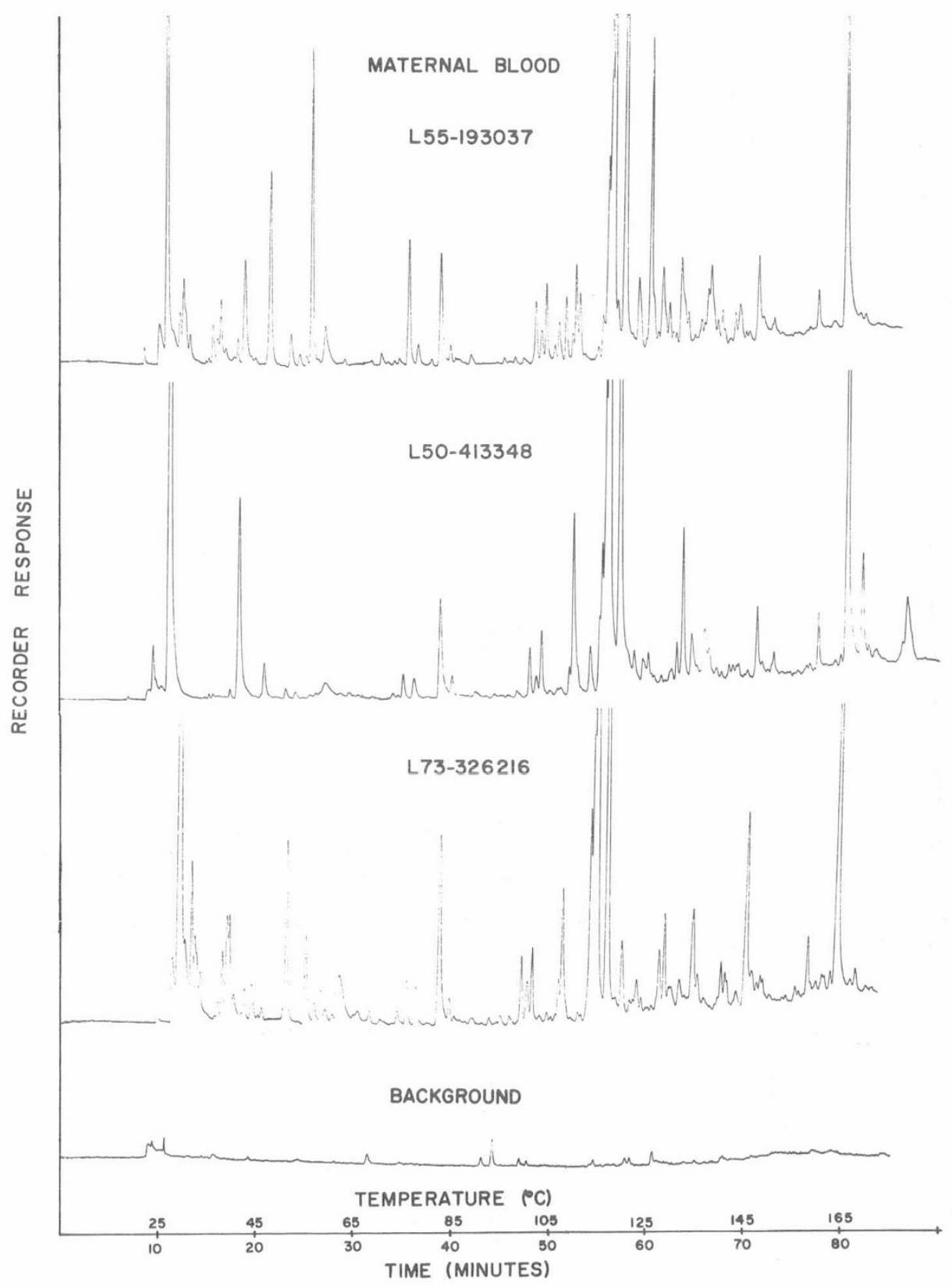

Fig. 1. Comparison of chromatographic profile obtained from 10-ml maternal blood samples collected before delivery for L55-193037 (upper trace); L50-413348 (second trace); L73-326216 (third trace); and a glassware, 50-ml artesian water aliquot, and chromatographic system background (lower trace). Chromatographic conditions are described in the text. 
themselves well as a method of routine clinical laboratory analysis. In this study, a simpler, less time-consuming method is used to obtain extracts suitable for GC-MS analysis from cord blood and maternal blood samples. This technique has been used previously to identify halogenated compounds in blood, tissues, and water samples $(7,8,21)$ and to monitor the efficiency of hemodialysis (9).

In neonates, investigators have demonstrated the transplacental passage of antiepileptic drugs, aspirin, and maternal analgesics (2, $11,19,20)$. Their presence in breast milk has also been reported (14). Chemicals may be present in the body fluids of a gravid female as a result of ingestion of medications, environmental exposure, including air, food, and water, or as a reflection of her own imbalance of metabolism such as in diabetes mellitus. Developmental changes in the embryo and fetus have been associated with maternal ingestion of folic acid antagonist, adrenal cortical steroids (3), and antiepileptic drugs (13).

Recent studies have identified organic compounds with molecular weights below 250, including halogenated hydrocarbons, in the drinking water of a large metropolitan area (8). Plasma levels of a selected portion of the population of this area were reflective of these compounds, suggesting a possible source for their environmental origin (8). Additionally, the presence of phthalates in neonatal tissues has also been reported by exposure of the neonate to plastic catheters $(10)$.

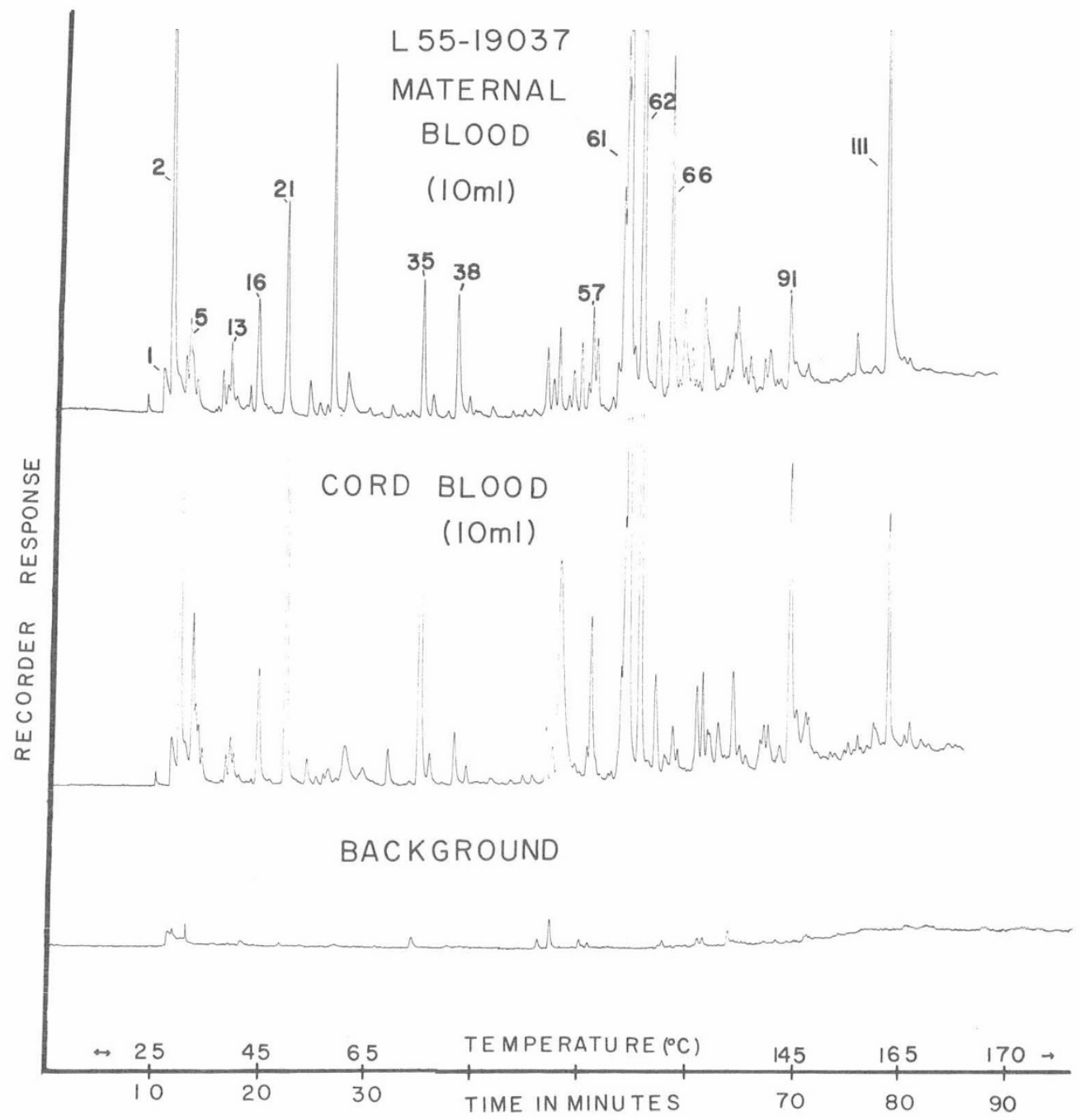

Fig. 2. Comparison of chromatographic profile obtained from $10 \mathrm{ml}$ maternal blood (upper trace); $10 \mathrm{ml}$ cord blood (middle trace) from L55-19037; and a glassware, 50- $\mathrm{ml}$ artesian water aliquot, and chromatographic system background (lower trace).

Gas chromatography peak no.

Compound identification

\begin{tabular}{cl}
\hline 2 & Acetone \\
7 & Dichloromethane \\
16 & Chloroform \\
21 & Benzene and carbon tet rachloride \\
22 & Pentan-2-one \\
50 & Ethyl benzene \\
52 & Xylene \\
57 & Styrene \\
73 & Trimethyl benzene \\
79 & Dichlorobenzene and dimethyl ethyl benzene \\
\hline
\end{tabular}


The purpose of this study is to report the presence of transplacentally acquired compounds, including plastic components and halogenated hydrocarbons, which have been detected in cord blood and maternal blood samples, using gas chromatographymass spectrometry.

\section{METHODS AND MATERIALS}

\section{COLLECTION AND STORAGE OF SAMPLES}

Gravid women patients at term were admitted to the delivery unit of Charity Hospital in New Orleans. The prenatal history of each patient was normal. All deliveries were vaginal; regional anesthesia was used in all patients with the use of nitrous oxide anesthesia in three patients. The range of placental weight was $460-950 \mathrm{~g}$. Five percent dextrose in water was given to each mother intravenously upon admission to the delivery unit. Two 10-ml Vacutainers of maternal blood were also collected either before or immediately after delivery and were stored at $4^{\circ}$. Cord blood samples were collected at delivery in Vacutainers containing EDTA from Becton-Dickinson, Rutherford, N. J. and stored at $4^{\circ}$ until analyses were performed. Eleven paired cord bloodmaternal blood samples were collected. The mean infant birth weight was 3,057 $\mathrm{g}$ (range 2,495-3,289 $\mathrm{g}$ ). The 1- and 5-min Apgar scores in all patients were $\geq 7$. Physical examination at birth was normal except for infant L54-140675 who was noted to have a lumbosacral meningomelocele. All infants were appropriately grown for 38-42 weeks of gestation.

\section{ANALYTIC METHODS FOR SAMPLE ANALYSIS}

The following procedure for sample analysis was performed for each cord blood and each maternal sample. Ten-milliliter blood samples were diluted with $50 \mathrm{ml}$ artesian water (which had been tested chromatographically before addition to the blood and found to be virtually free of any volatile organics). Volatile organics contained in the blood sample were thermally removed by a stream of ultrapure helium. Stirring of this solution by a magnetic stir bar aided in displacement of these organics from solution. A condensor was used to remove excess water vapor. From the condensor the volatile organics were passed over $1 \mathrm{~g}$ Tenax, a solid absorbent (25), contained in a reservoir provided with a fritted disc base to allow exit of the gas stream. The round bottomed flask containing the blood sample, the side arm gas inlet tube, condensor, and collection reservoir were all connected by either glass joints or ball and socket joints to form a leak-proof system. The manner in

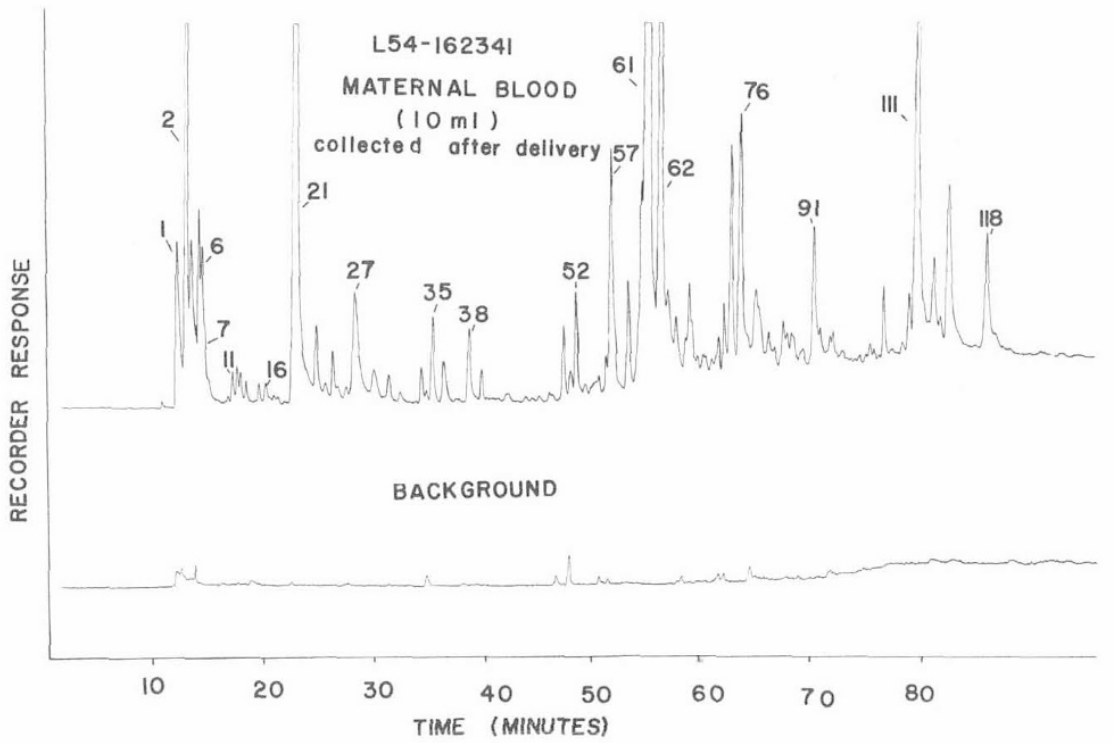

Fig. 3. Chromatogram of $10 \mathrm{ml}$ maternal blood (upper trace) collected after delivery from L54-162341, and a glassware, 50-ml artesian water aliquot, and chromatographic system background (lower trace).

Gas chromatography peak no.

$\begin{array}{ll}2 & \text { Acetone } \\ 7 & \text { Dichloromethane and isobutanol } \\ 12 & \text { Methyl ethyl ketone } \\ 15 & \text { Methyl cyclopentane } \\ 16 & \text { Chloroform } \\ 17 & 1,1-\text { Dichloro-1-nitroethane } \\ 21 & \text { Benzene and cyclohexane } \\ 22 & \text { Pentan-2-one } \\ 28 & \text { Methyl isobutyl ketone } \\ 29 & \text { Dimethyl disulfide } \\ 33 & \text { Toluene } \\ 50 & \text { Ethyl benzene } \\ 52 & \text { Xylene } \\ 56 & \text { Xylene } \\ 57 & \text { Styrene } \\ 59 & \gamma \text {-Heptalactone (tentative) } \\ 74 & \text { Benzaldehyde }\end{array}$


which the organics were collected involved no solvent extractions or clean-up procedures, thereby reducing the possibility of contamination from solvents, column packings, or error in handling. Because the compounds extracted were absorbed on a polymer, a modified form of injection into the gas chromatograph, instead of the conventional syringe injection, was used. The Tenax absorbent containing the absorbed organics was transferred to a silylated glass injection port liner $(10 \mathrm{~mm}$ in outside diameter, $9.2 \mathrm{~cm}$ in length), and each end was plugged with silylated glass wool. Additional details are published elsewhere (7).

The reason for pretreatment of the glass by silylation is to replace the free hydrogens on hydroxyl groups located on the glass surface with unreactive trimethyl silyl groups, $\mathrm{Si}\left(\mathrm{CH}_{3}\right)_{3}$. These glass liners containing the organics absorbed on the polymer were placed into the injection port (maintained at $200^{\circ}$ ) of a gas chromatograph (Hewlett-Packard 5750) which had been modified to accommodate liners of these dimensions. The volatiles were thus thermally desorbed from the polymer and transferred by means of a helium stream, which swept the injection port, onto a precolumn $(1.5 \mathrm{~m}$ by $0.05 \mathrm{~cm}$ ) coated with $10 \%$ GE SF-96 and $1 \%$ Igepal CO 880 stationary phases from Applied Science Laboratories. Separation of the organic components was achieved on this chromatographic capillary column by programming from ambient to $170^{\circ}$ at $2^{\circ} / \mathrm{min}$ after a 10 -min postinjection hold. Components were detected using a flame ionization detector which was held at $300^{\circ}$. The gas chromatographic effluent was vented through a heated transfer line $\left(200^{\circ}\right)$ into the mass spectrometer (DuPont 21-491) by a jet-type separator. Spectra were obtained using a $70-\mathrm{eV}$ ionization voltage. Spectral data was processed by a PDP-12 LDP computer (26). Spectra thus obtained were identified by comparison with published spectra $(1,23)$.

All glassware used for analysis was thoroughly cleaned and baked for several hours at $165^{\circ}$. The procedural blanks which represent the bottom-most trace in all of the chromatographic figures represent the volatiles that were contributed by the glassware, helium gas, and a $50-\mathrm{ml}$ aliquot of the artesian water used to dilute the blood sample. The contribution from these sources was negligible.

\section{RESULTS AND DISCUSSION}

Blood samples collected before delivery from gravid females at term show similar chromatographic profiles of the volatile constituents (Fig. 1). No marked differences in the chromatographic profiles of any of the 11 individuals studies were detected. Minor variations in the region of the earlier eluting, more volatile components were present; however, the consistency in all maternal profiles is adequate to establish a pattern characteristic of healthy, gravid females.

A comparison of volatile components in maternal and cord blood of one mother/infant pair is illustrated in Figure 2. In all patients, the cord blood closely corresponds to those quantities present in the maternal blood. However, some of the components are present in the cord blood in significantly higher concentrations than in the maternal blood, suggesting a possible selective, one-way transfer of certain constituents into the fetus. Identification of some of the components in the blood samples was achieved by combined gas chromatographic-mass spectrometric analyses, and a listing of those components thus identified with their corresponding chromatographic peak numbers can be found in the legend to Figure 2. Identification of only a fraction of the over 100 components has been achieved thus far.

Although some of the compounds identified in the normal subjects discussed above have been identified previously in urine specimens from patients with diabetes mellitus and in blood samples from hemodialysis patients, we are unaware of previous

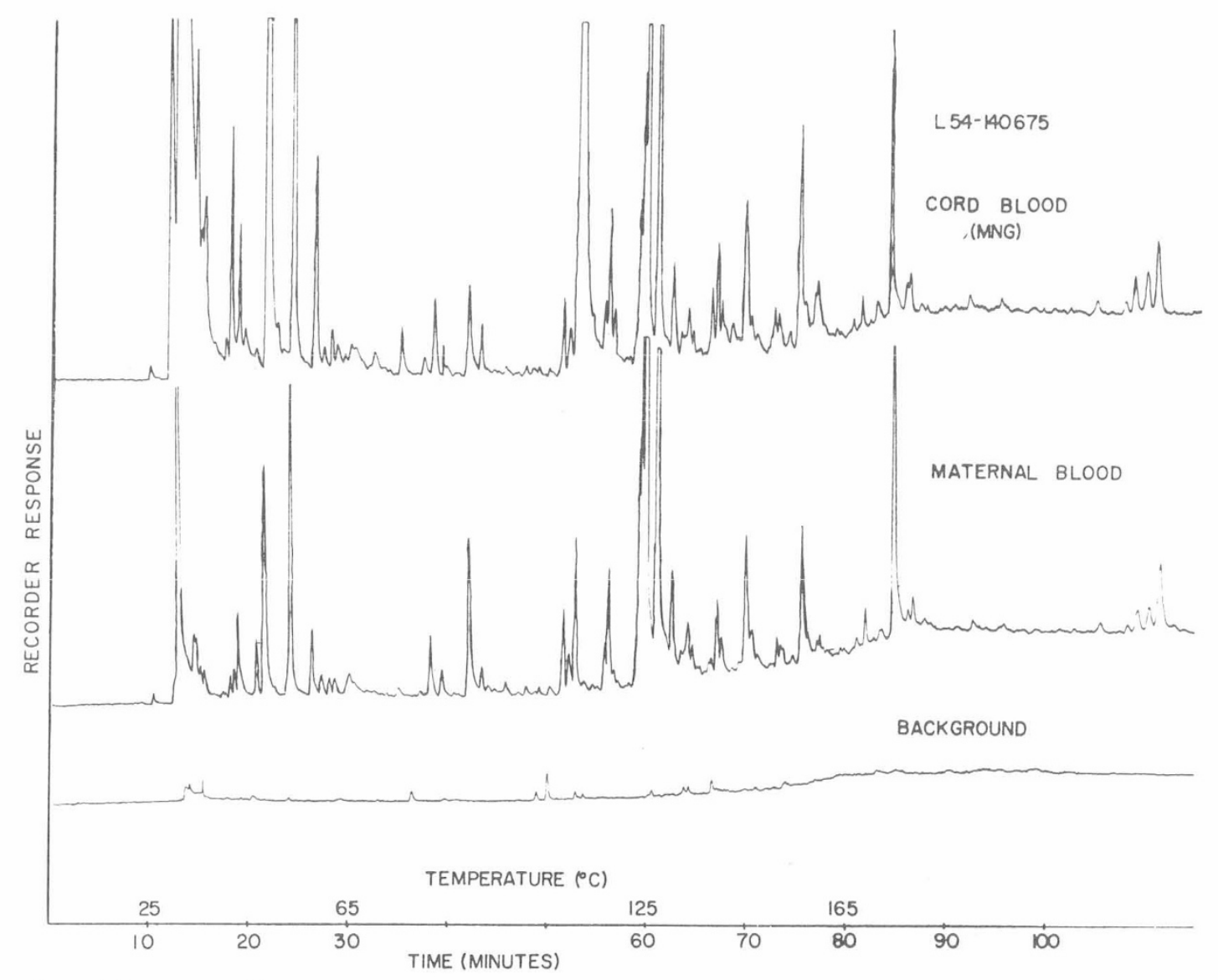

Fig. 4. Comparison of chromatographic profile obtained from $10 \mathrm{ml}$ cord blood (upper trace); $10 \mathrm{ml}$ maternal blood (middle trace) from L54-140675; and a glassware, $50-\mathrm{ml}$ artesian water aliquot, and chromatographic system background (lower trace). 
reports of the transplacental passage of such halogenated hydrocarbons, plastic components, and food preservatives. Benzene, carbon tetrachloride, and chloroform are present in quantities equal to or greater than those in maternal blood. These volatile compounds have been associated with liver toxicity (17) and carcinogenesis (15). Although their toxicity has been demonstrated primarily in laboratory animals, their toxicity in humans is suspect. Xylene and styrene are plastic components with unknown toxicity. Tissue toxicity and teratogenetic effects for rapidly growing cells from di-(2-ethyhexyl)phthalate (DEHP) have been a major area of concern (5). DEHP, a commonly used plasticizer, has been reported to be present in neonatal tissues after umbilical catheter placement and is found in high levels in infants dying with necrotizing enterocolitis (6).

In some cases maternal blood samples were collected immediately after delivery. A chromatogram of the profile obtained from one of the maternal blood samples collected after delivery is illustrated in Figure 3. The identification of the corresponding chromatographic peak numbers can be found in the legend to Figure 3. It is of interest to note that the concentrations of certain components, such as benzene and styrene, which are commonly associated with plastics, are enhanced in the blood samples collected from women after delivery. Perhaps this is related to the plastic infusion tubing used to deliver the infusion fluids to the mother while in labor. This is consistent with the findings of others who demonstrated the leaching of plasticizers into blood stored in plastic bags (24).

The profiles obtained for various individuals collected after delivery exhibited more variations between individuals than those profiles from the maternal blood samples collected before delivery, which were in good agreement. Therefore, for comparative purposes, collection of blood before delivery is probably more desirable.

In our profiling of maternal and cord blood samples, a normal healthy mother with a volatile blood profile consistent with those characteristics of healthy females gave birth to an infant with a lumbosacral meningomyelocoele (Fig. 4). The chromatogram of the cord blood of this infant shows certain inconsistencies as compared with profiles of healthy infants. Abnormally high concentrations of acetone and other components are present in this cord blodd specimen. In addition, BHT was identified. BHT, a food preservative with antioxidant properties, has been associated with renal, liver, and thyroid toxicity in laboratory animals (4).

\section{SUMMARY}

Gas chromatographic-mass spectrometric analyses of profiles of low molecular weight volatile organic constituents obtained from cord blood and maternal blood samples reflect transplacentally acquired compounds. The presence of halogenated hydrocarbons, plastic components, food preservatives, and abnormal accumulations of such compounds has been clearly demonstrated in fetal cord blood for the first time.

\section{REFERENCES AND NOTES}

1. Atlas of Mass Spectral Data, Vol. 1-3 (Interscience, New York, 1969).

2. Barr, M., Jr., Poznanski, A. K., and Schmickel, R. D.: Digital hypoplasia and anti-convulsants during gestation: A teratogenic syndrome. J. Pediat., 84(2): 254 (1974)
3. Beitins, I. Z., Bayard, F., Ances, I. G., Kowarski, A., and Migeon, C. J.: The transplacental passage of prednisone and prednisolone in pregnancy near term. J. Pediat., $81(5)$ : 936 (1972)

4. Chemical Abstracts, Toxicology Section, Vol. 76, 1972, Abstract 136615f; Chemical Abstracts, Toxicology Section, Vol. 78, 1973, Abstract 144156p.

5. DeHaan, R. L.: Toxicity in tissue culture media exposed to polyvinylchloride plastics. Nature New Biol., 85 (1971).

6. Dillingham, E. O., and Autain, J.: Teratogenicity, mutagenicity and cellular toxicity of phthalate esters. Environment Health Perspect, 3: 81 (1973).

7. Dowty, B. J., Carlisle, D. R., and Laseter, J. L.: New Orleans drinking water sources tested by gas chromatography-mass spectrometry. Environment. Sci. Technol., 9(8): 762 (1975).

8. Dowty, B., Carlisle, D., Laseter, J. L., and Storer, J.: Halogenated hydrocarbons in New Orleans drinking water and blood plasma. Science, 187: 75 (1975).

9. Dowty, B. J., Gonzalez, F., and Laseter, J. L.: Gas chromatographic study of low molecular weight volatiles during dialysis. Biomed. Mass Spectrom. (1975).

10. Hillman, L. S., Goodwin, S. L., and Sherman, W. R.: Identification and measurement of plasticizer in neonatal tissues after umbilical catheters and blood products. New Engl. J. Med. 292(8): 381 (1975).

11. Horning, M. G., Harvey, D. J., Nowlin, J., Stillwell, W. G., and Hill, R. M.: The use of gas chromatography-mass spectrometry methods in perinatal pharmacology. Advan. Biochem. Psychopharmacol., 7: 113 (1973).

12. Horning, E. C., and Horning, M. G.: Metabolic profiles: Gas-phase methods for analysis of metabolites. Clin. Chem., 17(8): 802 (1971).

13. Horning, M. G., Lertratangkoon, J., Nowlin, J., Stillwell, W. G., R. N. Zion, T. E., Kellaway, P., and Hill, R. M.: Anticonvulsant drug monitoring by GC-MS-COM techniques. J. Chromatogr. Sci., 12: 630 (1974).

14. Horning, M. G., Stillwell, W. G., Nowlin, J., Lertratanagkoon, K., Stillwell, R. N., and Hill, R. M.: Identification and quantification of drugs and drug metabolites in human breast milk using GC-MS-COM methods. Milk Lact. Mod. Probl. Paediat., 7: 73 (1975).

15. I.A.R.C. Report: On Evaluation of Carcinogenic Risk of Chemicals to Man (United Nations World Health Organization, Leone, France, 1972). International Agency for Research on Cancer Monograph, available from the American Public Health Association, Inc., Washington, D.C.

16. Jellum, E., Stokke, O., and Eldjarn, L.: Combined use of gas chromatography, mass spectrometry, and computer in diagnosis and studies of metabolic disorders. Clin. Chem., 18(8): 800 (1972).

17. Klaassen, C. D., and Plaa, G. L.: Relative effects of various chlorinated hydrocarbons on liver and kidney function in dogs. J. Appl. Pharmacol., 10: 119 (1967).

18. Markey, S. P., Thobhani, H. A., and Hammond, K. B.: Identification of urinary metabolites by gas chromatography mass spectrometry. A Collection of Mass Spectral Data (Department of Pediatrics, University of Colorado Medical Center, 1972).

19. Mirkin, B. L.: Diphenylhydantoin: Placental transport, fetal localization, neonatal metabolism, and possible teratogenic effects. Pediat. Pharmacol. Ther., 78(2): 329 (1971).

20. Monson, R. R., Rosenberg, L. Hartz, S. C., Shapiro, S., Heinonen, O. P., and Slone, D.: Diphenylhydantoin and selected congenital malformations. N. Engl. J. Med., 289(20): 1049 (1973).

21. Politzer, I. R., Githens, S., Dowty, B. J., and Laseter, J. L.: Gas chromatographic evaluation of the volatile constituents of lung, brain and liver tissues. J. Chromatogr. Sci., 13: 378 (1975).

22. Robinson, A. B., Partridge, D., Turner, M., Teranishi, R., and Pauling, L.: An apparatus for the quantitative analysis of volatile compounds in urine. J. Chromatogr., 85: 19 (1973).

23. Stenhagen, E., Abrahamson, S., and McLafferty, R. W.: Eight Peak Indexes of Mass Spectra, Vols. 1 and 2 (Mass Spectrometry Data Center Atomics Weapons Research Establishment, Aldermaston, England, 1970).

24. Vessman, J., and Rietz, G.: Determination of di(ethylhexyl) phthalate in human plasma and plasma proteins by electron capture gas chromatography. J. Chromatogr., 100: 154 (1974).

25. Tenax, GC 35/60 mesh, Applied Science Laboratories, State College, Pa.

26. Digital Equipment Corporation, Maynard, Mass.

27. These investigations were approved by the Human Experimentation Committees of the Louisiana State University School of Medicine and Charity Hospital in New Orleans.

28. We would like to thank Mr. D. Carlisle, Miss E. Motty, and Mrs. C. Jas for technical assistance.

29. Requests for reprints should be addressed to: J. L. Laseter, M.D., University of New Orleans, Department of Biological Sciences, Lakefront, New Orleans, La. 70112 (USA).

30. Accepted for publication February 13, 1976. 